\title{
Subtotal Hepatectomy for Primary Hepatic Carcinoma
}

\author{
G. E. MOLONEY,* M.A., M.B., M.R.C.P., F.R.C.S., F.R.C.S.ED.
}

Brit. med. F., 1967, 2, 809-810

The following case of a young woman who underwent an extensive resection of liver for a central hepatoma and remains well after four years is of interest.

\section{Case Report}

The patient, a married woman aged 18, was delivered of a normal child on 24 February 1962 . In the following month she had an upper abdominal right-sided dull ache for a week. Four months later she was admitted to the Radcliffe Infirmary, under Dr. P. Mallam, with headaches, enlarged glands in the neck, diarrhoea, generalized and right upper quadrant pain, and then jaundice, which on detailed investigation appeared to be obstructive, with a serum bilirubin of $8 \mathrm{mg} . / 100 \mathrm{ml}$. A mild fever settled in five days, the pain and the jaundice in nearly a month. Two cholecystograms showed faint filling of the gall bladder, but no stones. Jaundice and pain in the right upper quadrant recurred a few days later, with frequent loose pale stools, and after repeated investigations exploration was requested for obstructive jaundice.

First Operation.-At laparotomy on 7 September 1962 the liver was considerably enlarged and hard, the gall bladder tense but otherwise normal, and the bile duct much dilated and rubbery with soft contents. As the other abdominal organs were normal, the liver was closely examined and found to contain a tumour on the anterosuperior aspect, reaching to about an inch $(2.5 \mathrm{~cm}$.) from the falciform ligament, the surface being involved for about 2 in. $(5 \mathrm{~cm}$.). On choledochotomy the bile duct was found to be filled with plugs of material resembling curled-up soggy cigar leaves, presumed to result from portions of tumour ulcerating into a large duct. After clearance the bile duct was drained by a T-tube. A biopsy of the tumour revealed a primary liver-cell carcinoma with mild hepatitis and fine cirrhosis, while the material from the bile duct showed similar tumour cells. The jaundice cleared rapidly, and with the blood chemistry normal a wide resection was decided on as the only chance of effective treatment.

Second Operation.-Subtotal hepatectomy was performed on 21 September. The previous midline epigastric incision was reopened and extended into the seventh rib interspace, and the diaphragm was incised to allow adequate exposure. The cystic duct was divided. Access into the portal fissure was difficult, partly because of the choledochostomy, mainly on account of the hardness of the liver, but eventually the right hepatic artery, the right branch of the portal vein, and the right hepatic duct were identified, divided, and ligatured or sutured. On the superior aspect the right hepatic vein was tied with difficulty, again because of the hard liver, which also hindered its rotation for the division of about a dozen small branches passing direct into the inferior vena cava. A difference in colour of the right half of the liver was evident after all these ligations, but the tumour extending on the surface to within an inch $(2.5 \mathrm{~cm}$.) of the falciform ligament was well into the left half. The incision through the liver tissue had to be made just to the right of the falciform ligament, so it transected the left half of the liver, which still had a full blood supply. The hard rigid liver tissue prevented control of bleeding by clamps, artery forceps, or oversewing of the vessels, so that manual compression was the only means of reducing the marked bleeding while the liver was sectioned. Mattress suturing parallel to the edge and sutures across the cut surface finally achieved control. The remaining portion of the left lobe was still a large piece of liver. The bile duct was cleared and a $\mathrm{T}$-tube reinserted and underwater drains were placed in both the pleural cavity and the subphrenic space.

Postoperative Course.-Jaundice and mental confusion began on the second day, and a week later wild confusion and violence

* Consultant General Surgeon, Radcliffe Infirmary, Oxford. developed, which needed strong sedation for several weeks. Whether this mental state resulted only from diminished liver function was not certain. Both the cut surface of the liver and the common duct drained bile from the time of operation, but at 10 days the subhepatic tube dried up and was removed, the $\mathrm{T}$-tube being removed three weeks later after a satisfactory cholangiogram. Nearly six weeks after operation persistent pyrexia led to a subphrenic abscess being drained, a recognized complication where necessary tight suturing has led to liver sloughs-in this instance perhaps fortunate, as it may have resulted in an added removal of invaded tissue. Two months after operation the patient went home with her mentality restored, but the left lobe of the liver was palpable about 4 in. $(10 \mathrm{~cm}$.) into the epigastrium. After a further six weeks the left lobe had become impalpable and has stayed so. Four years later the liver was impalpable, the chest $x$-ray picture normal, and the patient very well. Her child was ready for school and another was hoped for.

\section{Pathological Report on Excised Liver (Dr. W. C. D. Richards)}

Macroscopic Appearance.-The neoplasm was roughly spherical in shape, measured $6 \mathrm{~cm}$. in diameter, extended to within $0.3 \mathrm{~cm}$. of the line of hepatic section, and projected into a large bile duct up to its line of section on the inferior surface of the liver. The gall bladder showed no evidence of malignancy. The hepatic tissue generally showed an accentuated lobular pattern suggestive of very early cirrhosis.

Microscopy.-The sections showed a malignant hepatoma composed of large pleomorphic hepatic cells with mitotic figures infrequent but many binucleate forms. Many cells were secreting bile, and bile thrombi were seen within the cells and also in small acinar formations. There was no evidence of normal hepatic lobular architecture in the tumour tissue. The growth was invading the adjacent hepatic parenchyma and had invaded a large bile duct. The non-neoplastic hepatic tissue showed an increase in fibrous tissue in the portal tracts, with some focal cellular infiltration of these areas and some proliferation of bile ducts. There was evidence of bile retention in the cells at the periphery of the hepatic lobules and occasional bile thrombi were also present. It was a malignant hepatoma.

The weight of the resected portion of liver, including a neoplasm $6 \mathrm{~cm}$. in diameter, was $1,300 \mathrm{~g}$.; a normal liver for a 9-stone $(55-\mathrm{kg}$.) subject weighs about $1,000 \mathrm{~g}$. About a third of the liver volume remained to the patient, the resection amounting to some two-thirds of a liver twice the normal weight.

\section{Biochemistry}

This was under the direction of Mr. J. R. P. O'Brien. Plasma proteins were normal (total $7.3 \mathrm{~g} . / 100 \mathrm{ml}$. and albumin $4.3 \mathrm{~g}$.) during the first admission on 28 June 1962. They were not measured again until three days after subtotal hepatectomy, and the ensuing changes are shown in Fig. 1. The bilirubin (see Fig. 2), normal at the time of the resection operation, rose on the fifth day to $24 \mathrm{mg} . / 100 \mathrm{ml}$., but thereafter rapidly fell, as shown in Fig. 2 . In a liver reduced by surgery to about one-third in size the same volume of portal blood must squeeze through this remnant and is bound to dilate the vessels, press on the liver cells, and narrow the bile canaliculi. This is the likely explanation of the jaundice which began immediately after the second operation. The blood urea fell after resection (see Fig. 2), and reached the low level of $6 \mathrm{mg}$./ $100 \mathrm{ml}$. on the $33 \mathrm{rd}$ day. This appeared to be due to a reduced ability of the liver to manufacture urea for a time while the kidneys 
were functioning well, and to some degree resulted from intravenous therapy. When on the 15 th day the blood urea was $8 \mathrm{mg}$. the urea content of the urine was $1.4 \mathrm{~g} . / 100 \mathrm{ml}$. At six weeks after operation the blood urea had returned to normal, no doubt with the improvement of liver function.

\section{Discussion}

Formal resection of the left lobe of the liver with preliminary ligation of the main left branch of the hepatic duct, portal vein, of the adverse factors of the narrow margin of resection to the edge of growth of only $0.3 \mathrm{~cm}$., and that pieces of the tumour had been sloughing into the bile duct, causing a rare form of recurrent jaundice, the patient is very well four years later. Evidently surgery of this nature, even in the young, is well worth attempting.

A viral infection might have been responsible for the fine cirrhosis and mild hepatitis, but most likely the hard and large liver with its cellular changes resulted solely from recurrent and prolonged jaundice due to obstruction by sloughs of
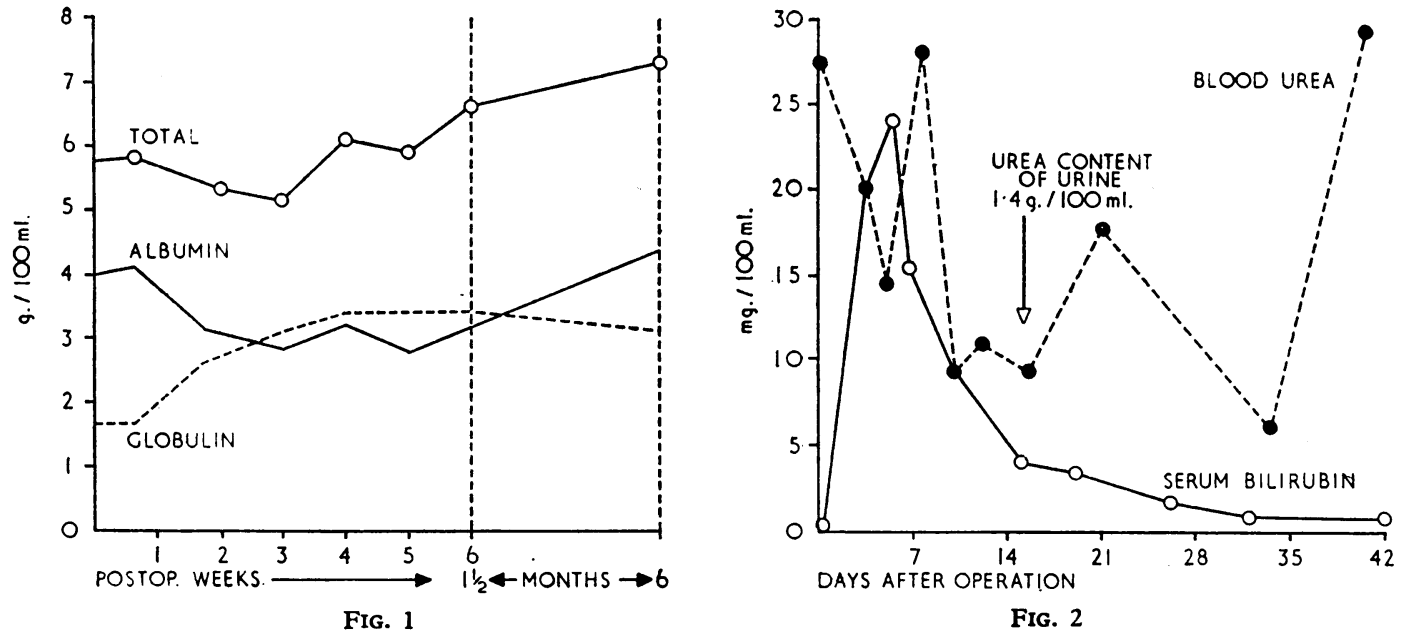

FIG. 2

FIg. 1.-Showing fall of total plasma proteins and reversal of albumin : globulin ratio after subtotal hepatectomy, and later return to normal. FIG. 2.- Showing fall of blood urea and rise of serum bilirubin after subtotal hepatectomy, and later return to normal.

and hepatic artery was not begun until after the second world war, when Pettinari (1947) described the operation for secondary deposits in the left lobe. Raven (1949) described a similar operation. Formal resection of the right half of the liver was first described by Lortat-Jacob and Robert (1952); they called it "hepatectomie droite reglée." The operation had its roots deep in Europe but was quickly adopted in the United States by Pack and Baker (1953), who added valuable experience.

The coming of abdomino-thoracic incisions stimulated by resection for gastric and oesophageal carcinoma, together with the arrival of the idea of pulmonary lobectomy with primary vascular ligation, no doubt paved the way for a notion of carrying out similar procedures in the case of lesions in the liver. Lloyd-Davies and Angell (1957) and Smith (1957) added to British experience, and Smith (1964) could cite some 14 resections of the right side, including two instances of a girl and a boy, both aged 13, who had had large malignant primary hepatic tumours, and who still survived three years after a right hemihepatectomy and a subtotal resection, respectively.

The present patient is the third recorded teenager to undergo this extensive operation successfully and to remain well after an appreciable interval. Perhaps these primary tumours in the young are not necessarily rapidly spreading types. In spite neoplasm in the bile ducts. In the two instances of primary hepatic neoplasia in the teenagers cited by Smith the surrounding liver was not recorded as abnormal.

\section{Summary}

A primigravida aged 18 was found at an operation for recurrent jaundice to have a malignant hepatoma in the centre of a large hard liver with curious sloughs of tumour blocking the common bile duct. Subtotal hepatectomy was carried out two weeks later. The clinical, operative, pathological, and biochemical features are outlined. The development of this operation is briefly reviewed and its value assessed.

\section{REFERENCES}

Lloyd-Davies, O. V., and Angell, J. C. (1957). Brit. F. Surg., 45, 113. Lortat-Jacob, J. L., and Robert, H. G. (1952). Presse méd., 60, 549. Pack, G. T., and Baker, H. W. (1953). Ann. Surg., 138, 253. Pettinari, V. (1947). Minerva med., 1, 134.

Raven, R. W. (1949). Brit. F. Surg., 36, 397.

Smith, R. (1957). Proc. roy. Soc. Med., 50, 152

- (1964). Ibid., 57, 547. 